\title{
Damage Identification in Structures Based on Energy Curvature Difference of Wavelet Packet Transform
}

\author{
Pengbo Wang $(\mathbb{D}$ and Qinghe Shi \\ Institute of Solid Mechanics, Beihang University (Beijing University of Aeronautics and Astronautics), Beijing 100191, China \\ Correspondence should be addressed to Pengbo Wang; pengbowang@buaa.edu.cn
}

Received 24 November 2017; Revised 25 March 2018; Accepted 31 March 2018; Published 28 May 2018

Academic Editor: Chao Tao

Copyright (C) 2018 Pengbo Wang and Qinghe Shi. This is an open access article distributed under the Creative Commons Attribution License, which permits unrestricted use, distribution, and reproduction in any medium, provided the original work is properly cited.

Damage identification is of tremendous significance in engineering structures. One key issue in damage identification is to determine an index that is sensitive to the structural damage. Current damage identification indices are generally focused on dynamic characteristics such as the natural frequencies, modal shapes, frequency responses, or their mathematical combinations. In this study, based on the wavelet packet transform, we propose a novel index, the energy curvature difference (ECD) index, to identify the damage in structures. The ECD index is the summation of component energy curvature differences after a signal is decomposed using WPT. Moreover, two numerical examples are used to demonstrate the feasibility and validity of the proposed ECD index for damage identification. Stiffness reduction is employed to simulate the structural damage. The damage can be identified by the ECD index curve plot. The results of the examples indicate that the proposed ECD index is sensitive to low damage levels because even $5 \%$ stiffness reduction can be apparently identified. The proposed ECD index can be employed to effectively identify structural damage.

\section{Introduction}

Damage is a serious threat to structures during their service life, and a damage identification technology is of tremendous significance in engineering applications. Once a structure is damaged, the dynamic characteristics of the structure, such as the modal shapes, natural frequencies, and frequency responses, will change [1]. Various methods have been proposed for the use of dynamic responses for damage identification [2-6]. These methods are regarded as vibration-based damage identification methods. Among these methods, the approach based on wavelet transform is playing an increasingly important role because it can focus on any detail of a signal in the time or frequency domain $[7,8]$.

The wavelet transform is an extension of the traditional Fourier transform and is capable of performing local and self-adaptive time-frequency analyses. Therefore, the wavelet transform can reveal some hidden phenomena of a signal that other signal processing techniques fail to observe $[9,10]$. This property has been introduced in the damage identification application. Numerous studies have been published regarding the use of wavelet transform for damage identification [11-15].
However, an obvious disadvantage of the wavelet transform is that the frequency resolution in the higher frequency domain is not high. It may be difficult to differentiate a signal containing high-frequency components that are very close to each other. Thus, scholars developed the wavelet packet transform (WPT) technique.

The WPT can be viewed as an extension of the traditional wavelet transform. It is capable of executing a complete levelby-level decomposition on a signal [16]. By performing the WPT on a signal, the signal can be decomposed into a series of wavelet packet components with a certain decomposition level, and the component energies can be obtained. The energy of the original signal is the summation of the component energies corresponding to different frequency bands. The WPT has been used for the damage identification of structures [17-20]. Wavelet packet energy can be obtained in different frequency bands after a signal is decomposed using WPT. The wavelet packet energy has been employed for the damage identification in ancient wood structures, beams, cable-stayed bridges, and so on [21-25]. Curvature difference can reflect the small changes in a function or a signal and has been introduced in damage identification 
together with wavelet packet energy. Some researchers have used curvature difference based on wavelet packet energy to locate the damage in ancient wood structures, concrete frames, and bridges [26-29].

One key issue in damage identification is to determine an index that is sensitive to the structural damage. Current damage identification indices are generally focused on dynamic characteristics such as the natural frequencies, modal shapes, frequency responses, or their mathematical combinations. In this study, based on the WPT, we propose a novel index, the energy curvature difference (ECD) index, to identify the damage in structures. The ECD index is the summation of component energy curvature differences after a signal is decomposed using WPT. It takes into account the spatial distribution of the collected signals and is sensitive to low damage levels because even a 5\% stiffness reduction can be apparently identified. Moreover, two numerical examples are used to demonstrate the feasibility and validity of the proposed ECD index for damage identification. Mutation on the ECD index curve can identify the damage accurately.

The remainder of this paper is organised as follows. In Section 2, some basics of the WPT are briefly introduced. In Section 3, an ECD index based on the WPT is proposed for damage identification. In Section 4, two numerical examples are provided to illustrate the applicability of the proposed ECD index. Section 5 presents the conclusions of this study.

\section{Basics of Wavelet Packet Transform}

The WPT is capable of accomplishing a complete level-bylevel decomposition of the signals. Wavelet packet $\psi_{j, k}^{i}(t)$ can be expressed as follows:

$$
\psi_{j, k}^{i}(t)=2^{-j / 2} \psi^{i}\left(2^{-j} t-k\right), \quad i, j \in \mathbf{Z}^{+}, k \in \mathbf{Z},
$$

where $i$ indicates the modulation parameter, $j$ indicates the scale parameter, and $k$ indicates the translation parameter. The wavelet packet functions possess the orthogonality property, i.e.,

$$
\psi_{j, k}^{m}(t) \cdot \psi_{j, k}^{n}(t)=0, \quad(m \neq n) .
$$

The first wavelet function is the mother wavelet function, i.e.,

$$
\psi^{1}(t)=\psi(t)
$$

Wavelet functions $\psi^{i}(t)$ can be calculated using the recursive equation

$$
\begin{aligned}
\psi^{2 i}(t) & =\sqrt{2} \sum_{k=-\infty}^{+\infty} h(k) \psi^{i}(2 t-k) \\
\psi^{2 i+1}(t) & =\sqrt{2} \sum_{k=-\infty}^{+\infty} g(k) \psi^{i}(2 t-k),
\end{aligned}
$$

where $h(k)$ and $g(k)$ are the quadrature mirror filters. $h(k)$ is related to the scaling function and $g(k)$ is related to the mother wavelet function.
Assume that $f(t)$ is a time signal. If $f(t)$ is decomposed to the $j$ th level, it can be expressed as

$$
f(t)=\sum_{i=0}^{2^{j}-1} f_{j}^{i}(t)
$$

where $f_{j}^{i}$ represents the $i$ th order wavelet packet component signal at level $j . f_{j}^{i}$ can be expressed by a linear combination of wavelet packet functions $\psi_{j, k}^{i}(t)$ in the following manner:

$$
f_{j}^{i}(t)=\sum_{k=-\infty}^{+\infty} c_{j, k}^{i}(t) \cdot \psi_{j, k}^{i}(t)
$$

where $c_{j, k}^{i}(t)$ represents the wavelet packet coefficient, expressed as

$$
c_{j, k}^{i}(t)=\int_{-\infty}^{+\infty} f(t) \cdot \psi_{j, k}^{i}(t) \mathrm{d} t
$$

WPT is a generalization of wavelet decomposition that offers a richer range of possibilities for signal analysis. In wavelet transform, a signal is split into an approximation and a detail. The approximation is then itself split into a secondlevel approximation and detail, and the process is repeated. In WPT, the details as well as the approximations can be split. This yields more different ways to encode the signal. The decomposition tree of WPT is plotted in Figure 1, where A represents the approximations and D represents the details, and $j$ denotes the decomposition level.

The energy of signal $f(t)$ at the $j$ th decomposition level is defined as

$$
E_{j}=\int_{-\infty}^{+\infty} f^{2}(t) \mathrm{d} t=\sum_{m=0}^{2^{j}-1} \sum_{n=0}^{2^{j}-1} \int_{-\infty}^{+\infty} f_{j}^{m}(t) \cdot f_{j}^{n}(t) \mathrm{d} t .
$$

Substituting (2) and (6) into (8) yields

$$
E_{j}=\sum_{i=0}^{2^{j}-1} E_{j}^{i}=\sum_{i=0}^{2^{j}-1} \int_{-\infty}^{+\infty}\left[f_{j}^{i}(t)\right]^{2} \mathrm{~d} t
$$

where $E_{j}^{i}$ represents the signal energy stored in the $i$ th order component signal at the $j$ th level. $E_{j}^{i}$ is regarded as the component energy of the WPT, and it can be expressed as follows:

$$
E_{j}^{i}=\int_{-\infty}^{+\infty}\left[f_{j}^{i}(t)\right]^{2} \mathrm{~d} t
$$

The physical implication of (10) is that the total energy stored in the original signal can be decomposed into a summation of the component energies, where each component corresponds to an individual frequency band.

\section{Damage Identification Based on Energy Curvature Difference}

One key issue of damage identification is to determine an index that is sensitive to structural damage. In this study, 


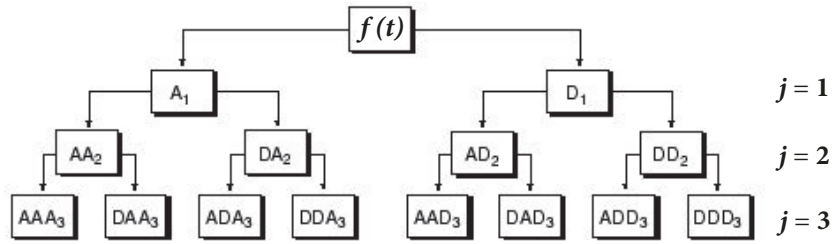

FIGURE 1: Decomposition tree of WPT ( $j$ is the decomposition level).

we propose an energy curvature difference (ECD) index to identify the damage in structures. The wavelet packet energy of a signal can be expressed as

$$
E=E_{j}^{0}+E_{j}^{1}+E_{j}^{2}+\cdots+E_{j}^{i}+\cdots+E_{j}^{2^{j}-1},
$$

where $i$ represents the order of the component signal and $j$ represents the decomposition level. We use the node acceleration responses of the structures as the signals to be analysed. These acceleration signals can be conveniently obtained by using acceleration sensors.

In practice, the curvature of a function $f(x)$ is usually obtained by using the second-order difference equation:

$$
f^{\prime \prime}\left(x_{i}\right)=\frac{\left(f\left(x_{i+1}\right)-f\left(x_{i}\right)\right) /\left(x_{i+1}-x_{i}\right)-\left(f\left(x_{i}\right)-f\left(x_{i-1}\right)\right) /\left(x_{i}-x_{i-1}\right)}{\left(\left(x_{i+1}-x_{i}\right)+\left(x_{i}-x_{i-1}\right)\right) / 2},
$$

where $x_{i-1}, x_{i}$, and $x_{i+1}$ represent three different points of variable $x$.

If the distance between $x_{i-1}$ and $x_{i}$ equals the distance between $x_{i}$ and $x_{i+1}$, i.e.,

$$
x_{i}-x_{i-1}=x_{i+1}-x_{i}=h,
$$

then in this case, (12) can be simplified as

$$
f^{\prime \prime}\left(x_{i}\right)=\frac{f\left(x_{i+1}\right)-2 f\left(x_{i}\right)+f\left(x_{i-1}\right)}{h^{2}} .
$$

The curvature is essentially a second-order difference of a function. Compared with the original function, the curvature is more sensitive to minor changes in the variable. This is an advantage of the curvature concept. Now, we introduce the concept of curvature into the wavelet packet energy for achieving damage identification. The component energy curvature is defined as

$$
\begin{aligned}
& \left(E_{j, k}^{i}\right)^{\prime \prime} \\
& =\frac{\left(E_{j, k+1}^{i}-E_{j, k}^{i}\right) / d_{k, k+1}-\left(E_{j, k}^{i}-E_{j, k-1}^{i}\right) / d_{k-1, k}}{\left(d_{k, k+1}+d_{k-1, k}\right) / 2},
\end{aligned}
$$

where $E_{j, k}^{i}$ denotes the energy related to the collected signal component $f_{j}^{i}(t)$ of the $k$ th node and $\left(E_{j, k}^{i}\right)^{\prime \prime}$ represents the curvature of $E_{j, k}^{i}$. Symbol $d_{k, k+1}$ represents the distance between the node $k$ and node $k+1$, and $d_{k-1, k}$ represents the distance between the node $k-1$ and node $k$. In particular, if $d_{k, k+1}$ is equal to $d_{k-1, k}$, i.e.,

$$
d_{k, k+1}=d_{k-1, k}=d
$$

then in this situation, (15) can be simplified as

$$
\left(E_{j, k}^{i}\right)^{\prime \prime}=\frac{E_{j, k+1}^{i}-2 E_{j, k}^{i}+E_{j, k-1}^{i}}{d^{2}} .
$$

From (17), it can be observed that, by using the curvature technique, the component energy change of a single node is transformed to the distribution change of the curvature values of three adjacent nodes. The spatial distribution of the component energies has been taken into account in (17). This technique can amplify the changes in a signal.

The component energy curvature difference is defined as

$$
\Delta\left(E_{j, k}^{i}\right)^{\prime \prime}=\left(E_{j, k}^{i}\right)_{d}^{\prime \prime}-\left(E_{j, k}^{i}\right)_{u}^{\prime \prime},
$$

where subscript $d$ denotes a damaged structure and subscript $u$ denotes an undamaged structure.

Now we perform a summation of the component energy curvature differences, and the summation is defined as the ECD index, expressed as

$$
E C D=\sum_{i=0}^{2^{j}-1} \Delta\left(E_{j, k}^{i}\right)^{\prime \prime}
$$

where $i$ is the order of the wavelet packet frequency band, $j$ is the wavelet packet decomposition level, and $k$ is the signal collection node number.

By substituting (18) into (19), the ECD index can also be expressed as follows:

$$
E C D=\sum_{i=0}^{2^{j}-1}\left[\left(E_{j, k}^{i}\right)_{d}^{\prime \prime}-\left(E_{j, k}^{i}\right)_{u}^{\prime \prime}\right] .
$$




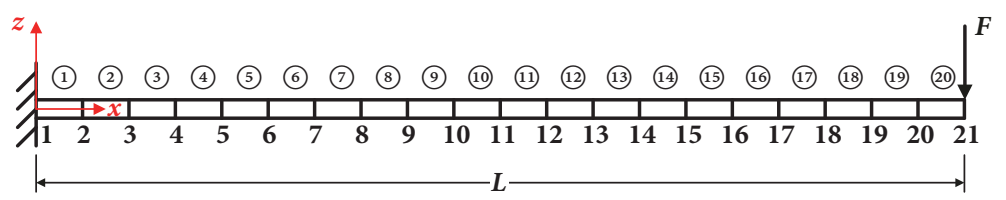

FIGURE 2: Cantilever beam under the action of an impact force.

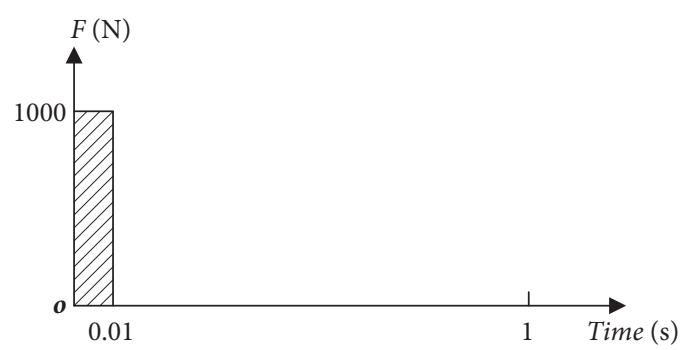

FIgURE 3: Force-time history curve for Example 1.

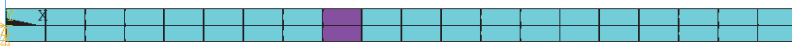

FIgURE 4: Location of damage element in case L1 in Example 1.

The numerical value of the ECD index is regarded as an indicator of the damage identification in structures. In practice, we collect the node acceleration response signals of the undamaged structure and damaged structure. Then, we perform WPT on the collected signals. With the calculation of the wavelet packet component energies, we can obtain the ECD indices. Subsequently, we can plot the ECD indices of different nodes in one figure. A mutation on the plot is indicative of damage in a structure. A sudden change in the ECD plot is indicative of a damage occurrence. The location and severity of the damage can be reflected by the ECD index plot.

The proposed method requires signals of both damaged and undamaged structure, which sometimes could be difficult to obtain. In practice, with acceleration sensors installed appropriately, the signals of both damaged and undamaged structure are accessible. Besides, finite elements method is commonly used in engineering and we can simulate the damage in a fine meshed finite element model. The proposed method can give accurate results for a finite element model with damage. This will be very useful in the initial design stage of a structure. Thus, the proposed method has extent of engineering values.

\section{Numerical Examples}

To demonstrate the feasibility of the proposed ECD index for damage identification of structures, the following two numerical examples are considered. Both the location and severity of the damage are investigated with the proposed damage identification index.

Example 1. Consider a cantilever beam under the action of an impact force, as shown in Figure 2. The length of the beam is $L=1 \mathrm{~m}$. The section moment of inertia of the beam is $I=1.6 \times 10^{-7} \mathrm{~m}^{4}$. Young's modulus of the material is $E=$ $210 \mathrm{GPa}$, the mass density is $\rho=7850 \mathrm{~kg} / \mathrm{m}^{3}$, and Poisson's ratio is $v=0.3$. It is assumed that there is an impact force $F$ acting at the endpoint of the beam in the vertical direction. The force-time history is plotted in Figure 3. The beam is discretized by 21 nodes and meshed with 20 elements. The node acceleration responses are calculated using the software ANSYS 15.0 and are regarded as the collected signals. The sampling frequency employed in this example is $10^{5} \mathrm{~Hz}$. The signals are decomposed to level 4 with Db10 wavelet, and 16 component energies are generated in total.

The element stiffness reduction can be used to simulate the structural damage. In practice, it is convenient to use Young's modulus reduction to characterize damage. In this example, we use two test cases to investigate the application of the proposed ECD index in damage location identification, as presented in Table 1. The locations of the damage elements in the finite element model are illustrated in Figures 4 and 6, and the corresponding ECD index curves are plotted in Figures 5 and 7, respectively. The damaged elements are displayed using a different color in the finite element model that it is employed for the verification of the proposed index.

We use four test cases to investigate the application of the proposed ECD index in damage severity identification, as presented in Table 2. The damage level of specific elements increases from $5 \%$ to $20 \%$. The ECD curves corresponding to all the four cases are plotted in Figure 8.

The decomposition tree of WPT in Example 1 is plotted in Figure 9. The tree consists of several knots. Knot $(j, i)$ represents the $i$ th order wavelet packet component signal at decomposition level $j$. 


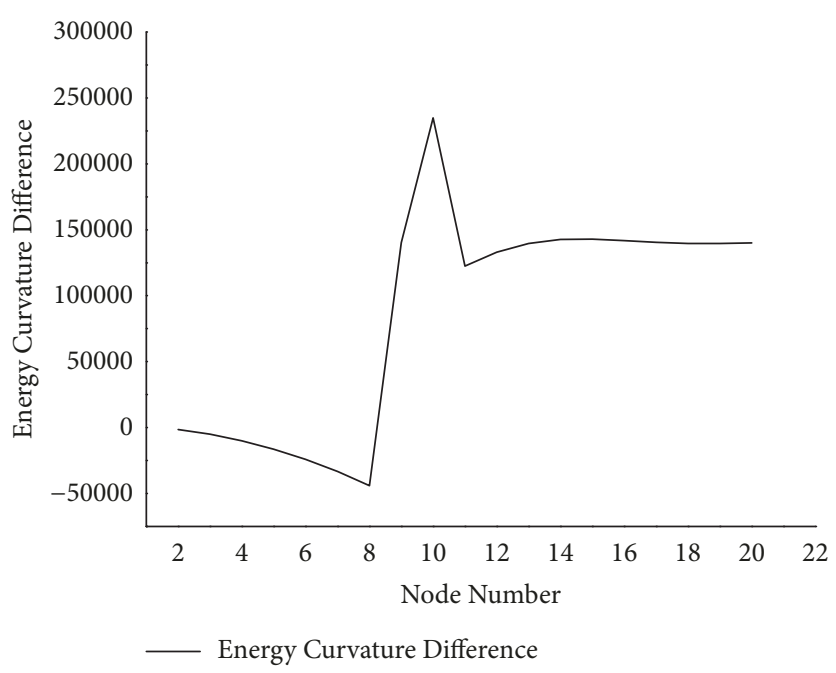

FIGURE 5: ECD index curve for damage location identification in case L1 in Example 1.

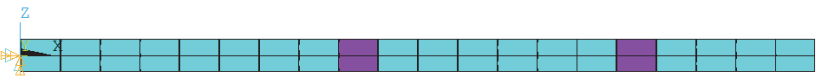

FIGURE 6: Locations of damage elements in case L2 in Example 1.

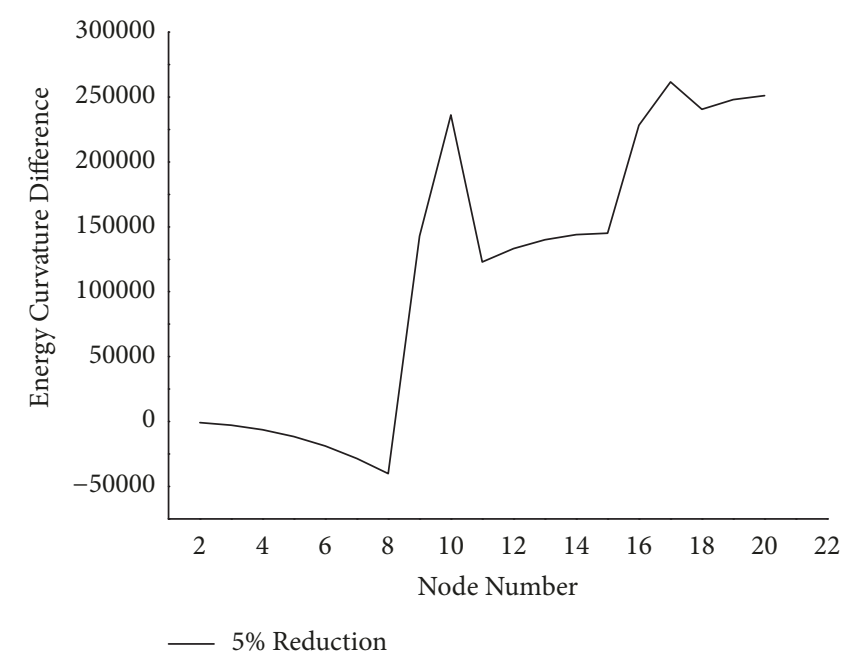

FIgURE 7: ECD index curve for damage location identification in case L2 in Example 1.

For graphical illustration, the wavelet packet coefficients corresponding to the 16th node in case S1 of knots $(1,0)$, $(1,1),(2,0),(2,1),(3,0),(3,1),(4,0)$, and $(4,1)$ are presented in Figure 10 .

From the plots in Figures 5 and 7, it can be observed that the proposed ECD index can identify the damage locations accurately. There is an obvious mutation on the ECD index curve at the location where the damage is present. Moreover, the ECD index is sensitive to low damage levels because even $5 \%$ stiffness reduction can be apparently reflected by the ECD index curve. From the plot in Figure 8, it can be observed that the damage severity can be reflected by the amplitude of the mutation point. For the same damage locations with different damage levels, the amplitudes of the mutation are higher for the cases that are more severely damaged. The results of this example indicate that the proposed ECD index can be employed to identify the damage location and damage severity effectively.

Example 2. Now, we consider a spatial frame structure under the action of an impact force, as shown in Figure 11. The dimensions are as follows: $h_{1}=1.6 \mathrm{~m}, h_{2}=1.5 \mathrm{~m}, l=1.8 \mathrm{~m}$, and $w=0.9 \mathrm{~m}$. The frame section is plotted in Figure 12 . The section dimensions are $b=0.1 \mathrm{~m}$ and $t=0.009 \mathrm{~m}$. Young's modulus of the material is $E=210 \mathrm{GPa}$, the mass density is $\rho=7850 \mathrm{~kg} / \mathrm{m}^{3}$, and Poisson's ratio is $v=0.3$. It is assumed that there is an impact force acting at point $\mathrm{D}$ in the $z$ direction. The force-time history is plotted in 
TABLE 1: Test cases for damage location identification in Example 1.

\begin{tabular}{lcccc}
\hline Case No. & Damage element & Damage location & Damage level & Young's modulus \\
\hline L1 & Element 9 & Between node 9 and node 10 & $5 \%$ & $210 \mathrm{GPa} \times 95 \%$ \\
L2 & Element 9 & Between node 9 and node 10 & $5 \%$ & $210 \mathrm{GPa} \times 95 \%$ \\
& Element 16 & Between node 16 and node 17 & $5 \%$ & $210 \mathrm{GPa} \times 95 \%$ \\
\hline
\end{tabular}

TABLE 2: Test cases for damage severity identification in Example 1.

\begin{tabular}{lcccc}
\hline Case No. & Damage element & Damage location & Damage level & Young's modulus \\
\hline \multirow{2}{*}{ S1 } & Element 9 & Between node 9 and node 10 & $5 \%$ & $210 \mathrm{GPa} \times 95 \%$ \\
& Element 16 & Between node 16 and node 17 & $5 \%$ & $210 \mathrm{GPa} \times 95 \%$ \\
S2 & Element 9 & Between node 9 and node 10 & $10 \%$ & $210 \mathrm{GPa} \times 90 \%$ \\
& Element 16 & Between node 16 and node 17 & $10 \%$ & $210 \mathrm{GPa} \times 90 \%$ \\
S3 & Element 9 & Between node 9 and node 10 & $15 \%$ & $210 \mathrm{GPa} \times 85 \%$ \\
& Element 16 & Between node 16 and node 17 & $15 \%$ & $210 \mathrm{GPa} \times 85 \%$ \\
S4 & Element 9 & Between node 9 and node 10 & $20 \%$ & $210 \mathrm{GPa} \times 80 \%$ \\
& Element 16 & Between node 16 and node 17 & & $210 \mathrm{GPa} \times 80 \%$ \\
\hline
\end{tabular}

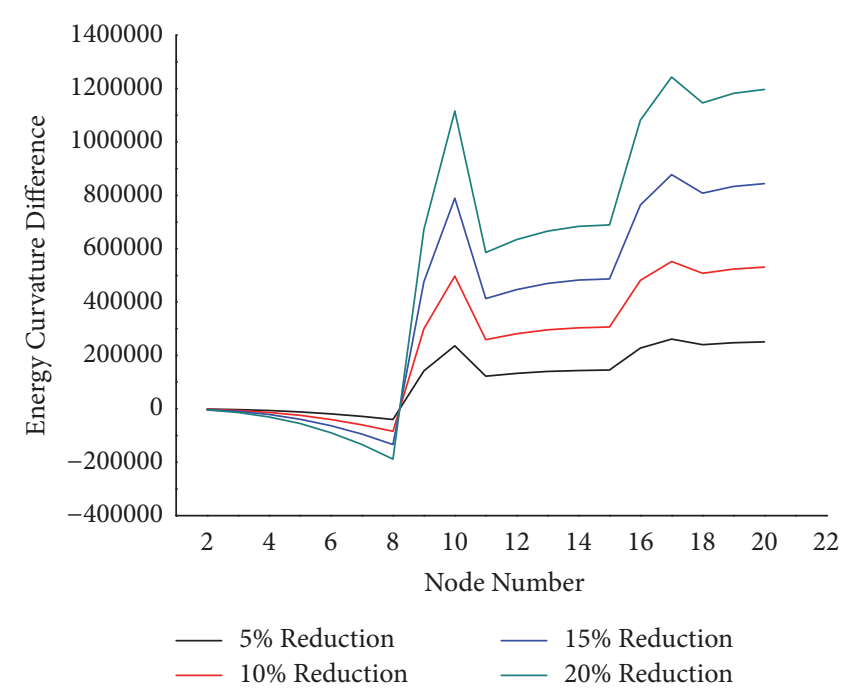

FIGURE 8: ECD index curve for damage severity identification in cases S1 to S4 in Example 1.

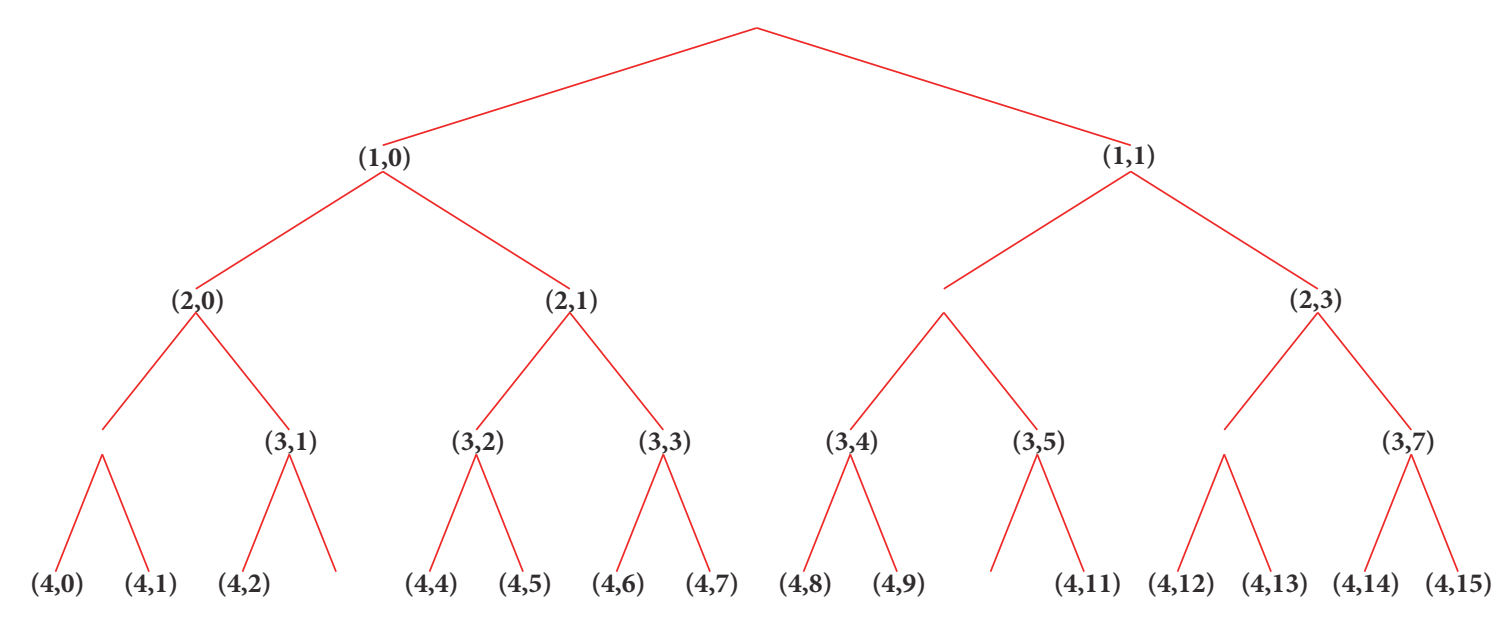

FIGURE 9: Decomposition tree of WPT in Example 1. 


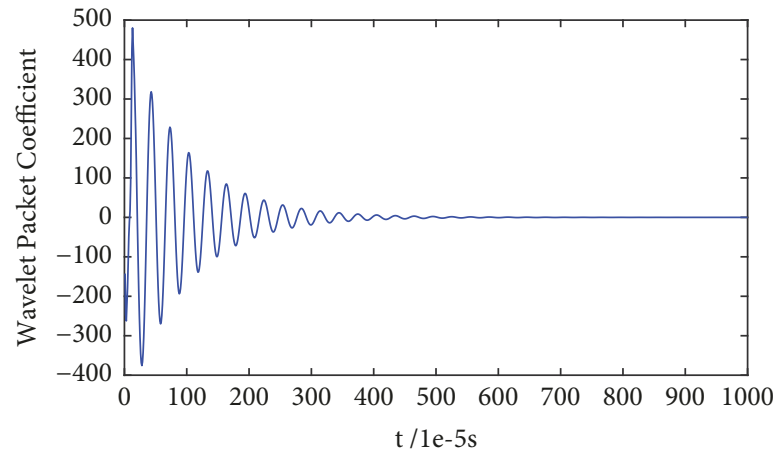

(a) $\operatorname{Knot}(1,0)$

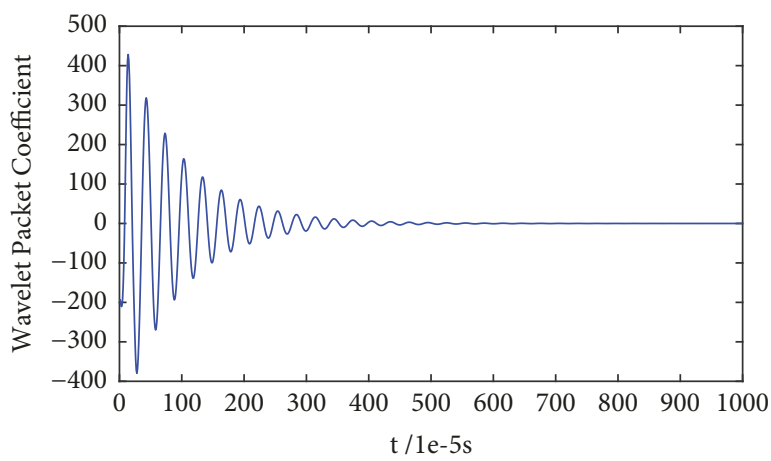

(c) $\operatorname{Knot}(2,0)$

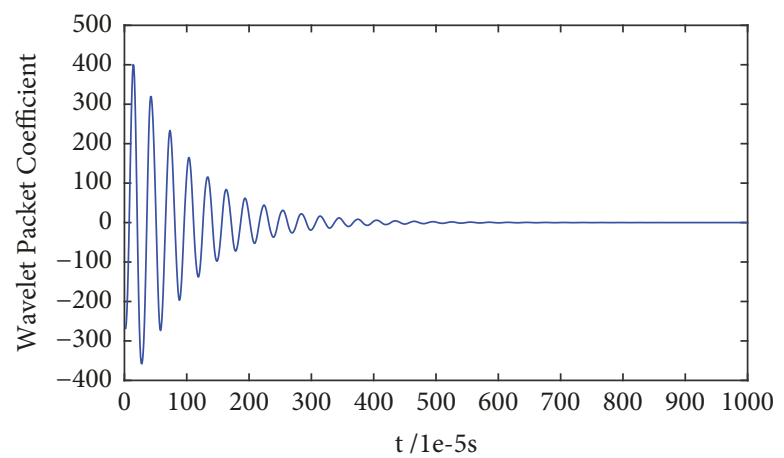

(e) $\operatorname{Knot}(3,0)$

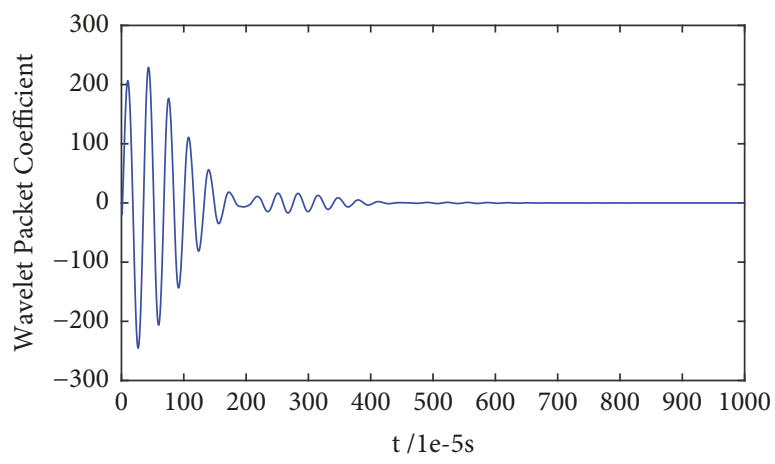

(g) $\operatorname{Knot}(4,0)$

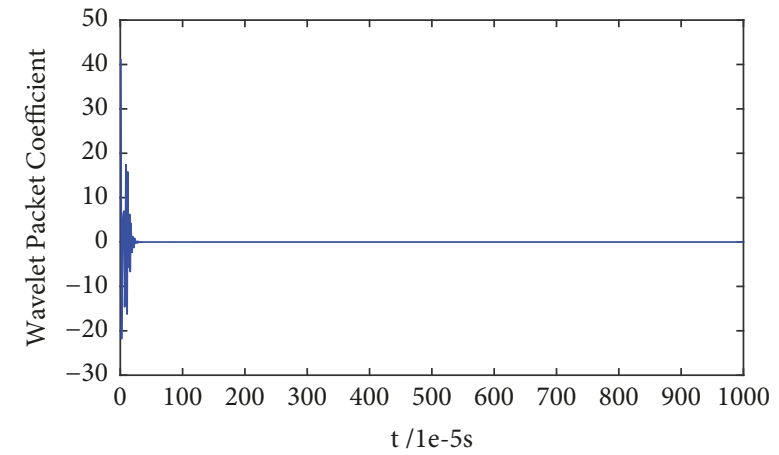

(b) $\operatorname{Knot}(1,1)$

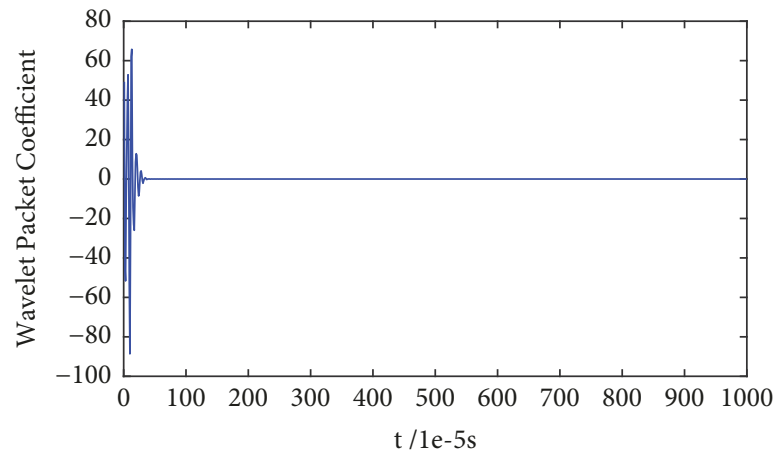

(d) $\operatorname{Knot}(2,1)$

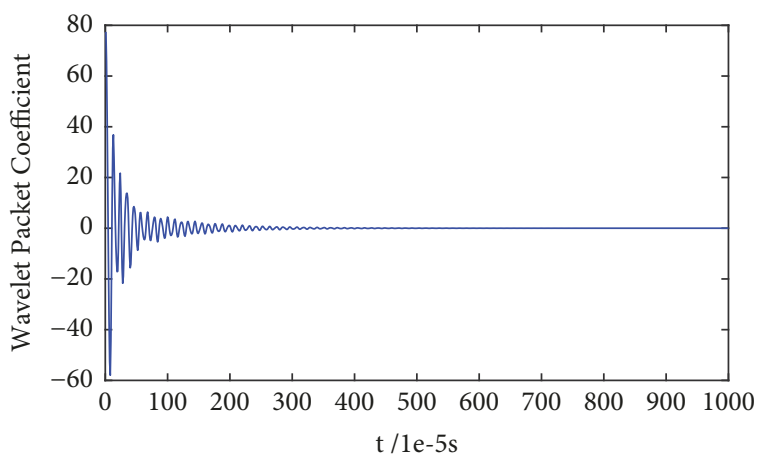

(f) $\operatorname{Knot}(3,1)$

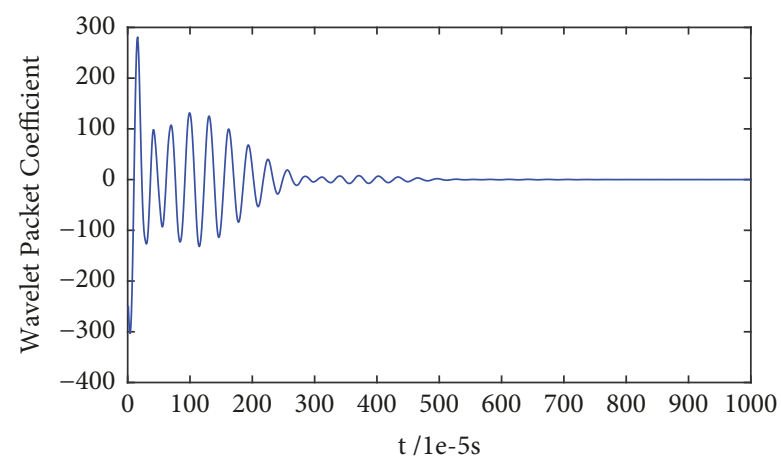

(h) $\operatorname{Knot}(4,1)$

FIGURE 10: Wavelet packet coefficients corresponding to the 16th node in case S1 in Example 1. 


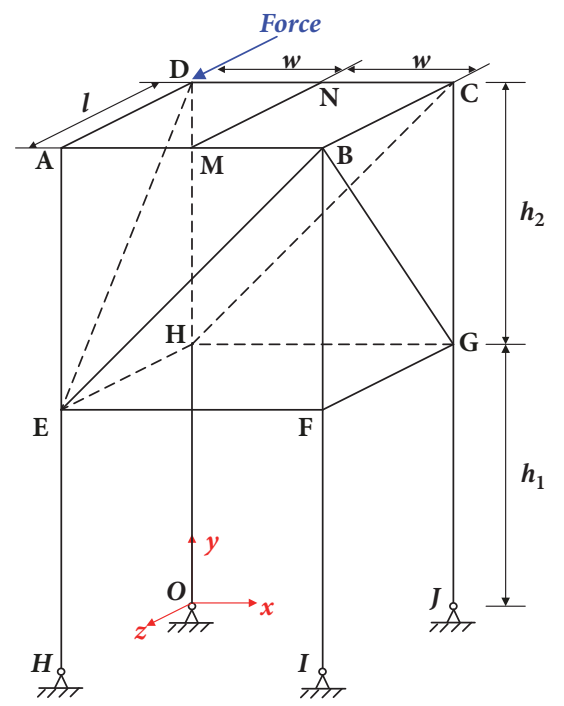

FIGURE 11: Spatial frame structure under the action of an impact force.

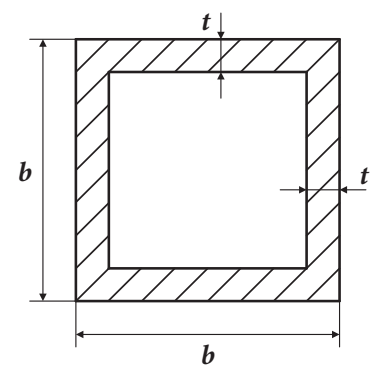

FIgURE 12: Illustration of the frame section.

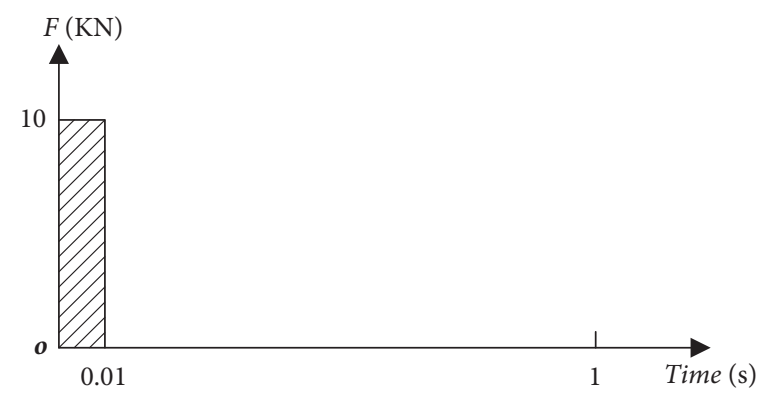

FIGURE 13: Force-time history curve for Example 2.

Figure 13. The structure is meshed with 760 beam elements. The node acceleration responses are calculated using the software ANSYS 15.0 and are regarded as the collected signals. The sampling frequency employed in this example is $2000 \mathrm{~Hz}$. The signals are decomposed to level 4 with Db10 wavelet, and 16 component energies are generated in total.

It is assumed that the damage occurs in the EF part. In the finite element model, the EF part is discretized by 36 elements. The element close to point $\mathrm{E}$ is numbered 1 , and the element close to point $\mathrm{F}$ is numbered 36. The length of each element is $0.05 \mathrm{~m}$. There are totally 37 nodes located in the EF part. The node at point $\mathrm{E}$ is numbered as the 1st node, and the node at point $\mathrm{F}$ is numbered as the 37 th node. The element numbers and node numbers in the EF part are illustrated in Figure 14.

The element stiffness reduction can be used to simulate the structural damage. In practice, it is convenient to use Young's modulus reduction to characterize damage. In this example, we use two test cases to investigate the application of the proposed ECD index in damage location identification, as presented in Table 3. The locations of the damage elements in the finite element model are illustrated in Figures 15 and 17 , and the corresponding ECD index curves are plotted in Figures 16 and 18, respectively. The damaged elements are displayed using a different color in the finite element model that it is employed for the verification of the proposed index. 


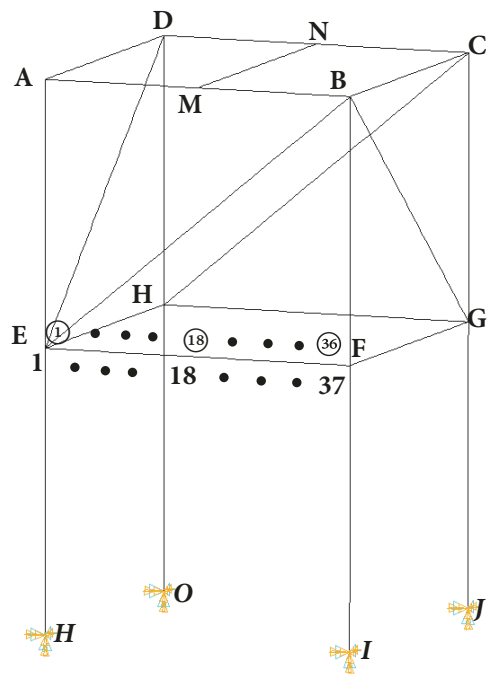

FIGURE 14: Element numbers and node numbers of the EF part.

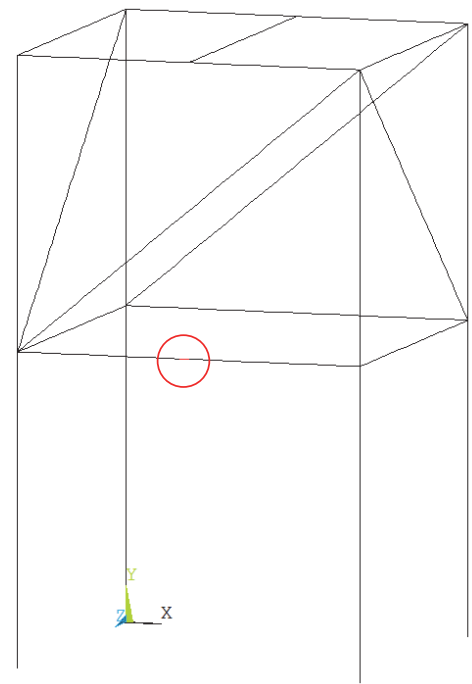

FIgURE 15: Location of damage element in case L1 in Example 2.

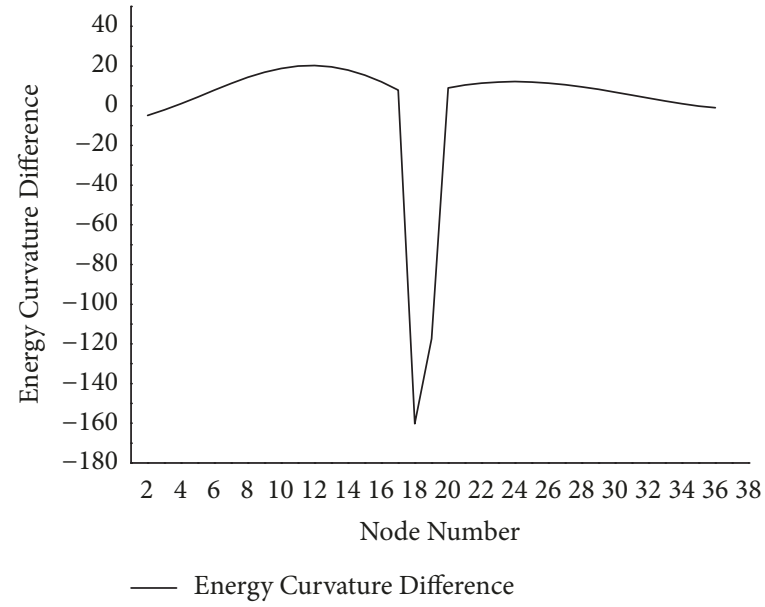

FIGURE 16: ECD index curve for damage location identification in case L1 in Example 2. 


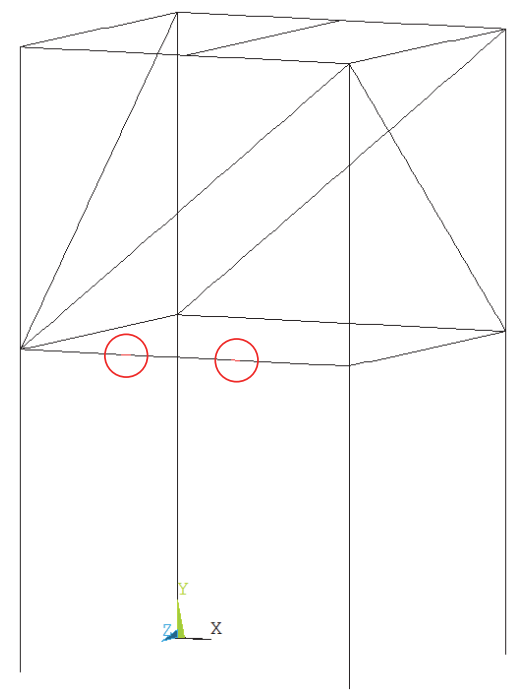

FIgURE 17: Locations of damage elements in case L2 in Example 2.

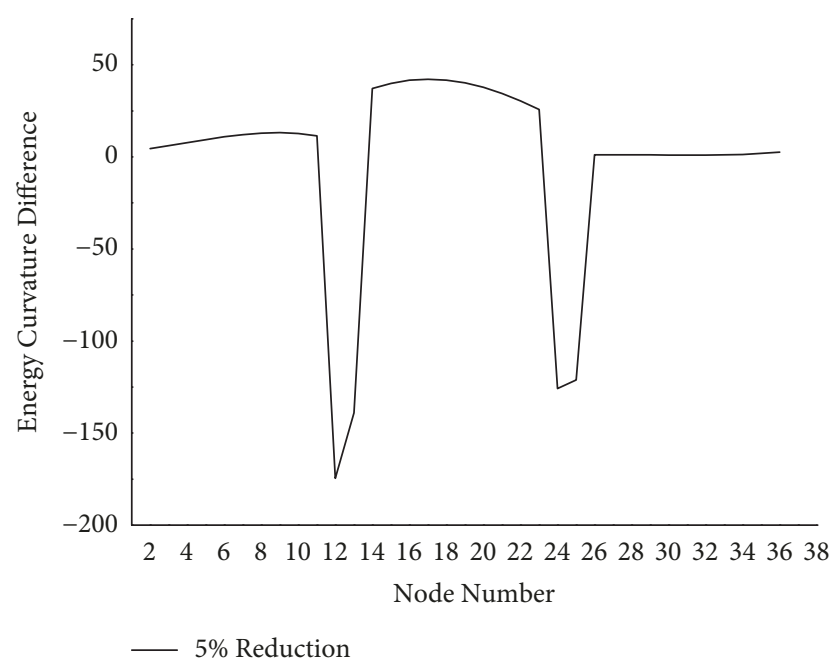

FIGURE 18: ECD index curve for damage location identification in case L2 in Example 2.

We use four test cases to investigate the application of the proposed ECD index in damage severity identification, as presented in Table 4 . The damage level of specific elements increases from $5 \%$ to $20 \%$. The ECD curves corresponding to all the four cases are plotted in Figure 19.

The decomposition tree of WPT in Example 1 is plotted in Figure 20. The tree consists of several knots. Knot $(j, i)$ represents the $i$ th order wavelet packet component signal at decomposition level $j$.

For graphical illustration, the wavelet packet coefficients corresponding to the 24 th node in case S1 of knots $(1,0)$, $(1,1),(2,0),(2,1),(3,0),(3,1),(4,0)$, and $(4,1)$ are presented in Figure 21 .

From the plots in Figures 16 and 18, it can be observed that the proposed ECD index can identify the damage locations accurately. There is an obvious mutation on the ECD index curve at the location where the damage is present. Moreover, the ECD index is sensitive to low damage levels because even $5 \%$ stiffness reduction can be apparently reflected by the ECD index curve. From the plot in Figure 19, it can be observed that the damage severity can be reflected by the amplitude of the mutation point. For the same damage locations with different damage levels, the amplitudes of the mutation are higher for the cases that are more severely damaged. The results of this example indicate that the proposed ECD index can be employed to identify the damage location and damage severity effectively.

\section{Conclusions}

In this study, we propose an ECD index based on the WPT to identify a structural damage. The node acceleration responses of the undamaged and damaged structures are collected. We perform WPT on the signals and compute the component 
TABLE 3: Test cases for damage location identification in Example 2.

\begin{tabular}{lcccc}
\hline Case No. & Damage element & Damage location & Damage level & Young's modulus \\
\hline L1 & Element 18 & Between node 18 and node 19 & $5 \%$ & $210 \mathrm{GPa} \times 95 \%$ \\
L2 & Element 12 & Between node 12 and node 13 & $5 \%$ & $210 \mathrm{GPa} \times 95 \%$ \\
& Element 24 & Between node 24 and node 25 & $5 \%$ & $210 \mathrm{GPa} \times 95 \%$ \\
\hline
\end{tabular}

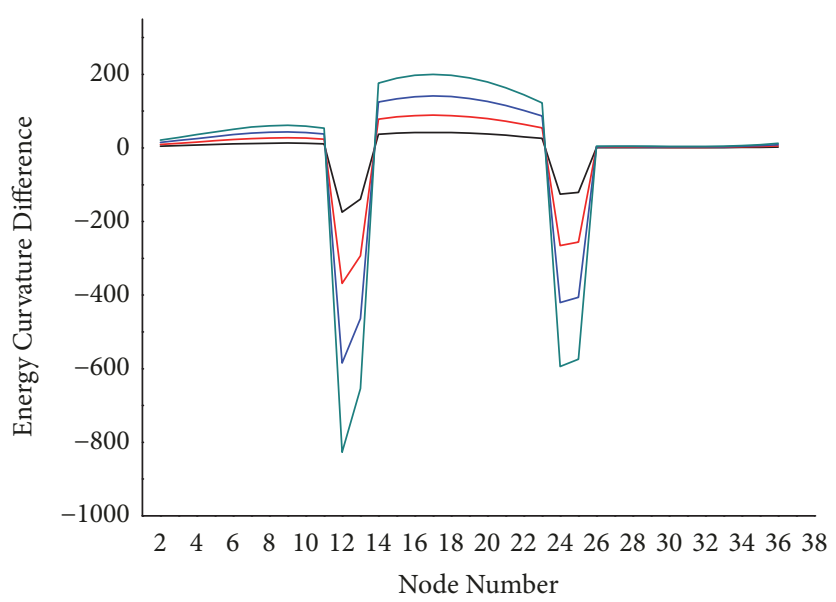

$\begin{array}{ll}-5 \% \text { Reduction } & -15 \% \text { Reduction } \\ -10 \% \text { Reduction } & -20 \% \text { Reduction }\end{array}$

FIGURE 19: ECD index curve for damage severity identification in cases S1 to S4 in Example 2.

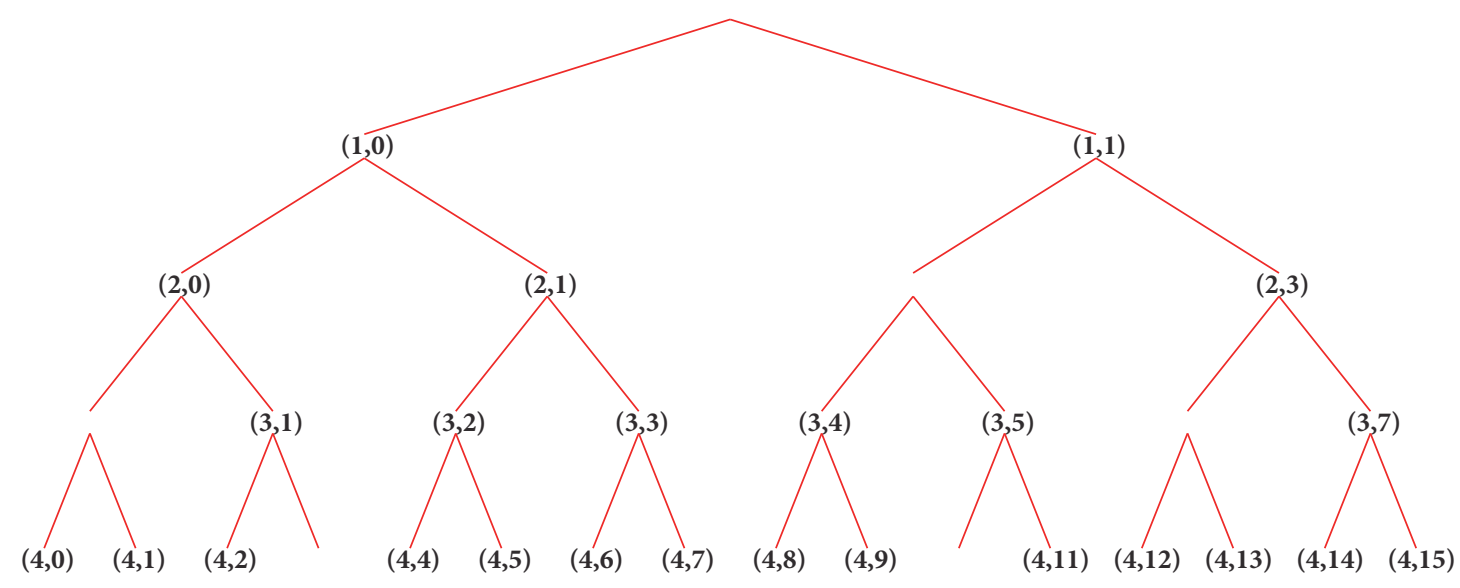

FIgURE 20: Decomposition tree of WPT in Example 2.

TABLE 4: Test cases for damage severity identification in Example 2.

\begin{tabular}{lcccc}
\hline Case No. & Damage element & Damage location & Damage level & Young's modulus \\
\hline S1 & Element 12 & Between node 12 and node 13 & $5 \%$ & $210 \mathrm{GPa} \times 95 \%$ \\
& Element 24 & Between node 24 and node 25 & $5 \%$ & $10 \%$ \\
S2 & Element 12 & Between node 12 and node 13 & $10 \%$ & $210 \mathrm{GPa} \times 95 \%$ \\
& Element 24 & Between node 24 and node 25 & $15 \%$ & $210 \mathrm{GPa} \times 90 \%$ \\
S3 & Element 12 & Between node 12 and node 13 & $15 \%$ & $210 \mathrm{GPa} \times 85 \%$ \\
& Element 24 & Between node 24 and node 25 & $20 \%$ & $210 \mathrm{GPa} \times 85 \%$ \\
S4 & Element 12 & Between node 12 and node 13 & $20 \%$ & $210 \mathrm{GPa} \times 80 \%$ \\
& Element 24 & Between node 24 and node 25 & & $210 \%$ \\
\hline
\end{tabular}




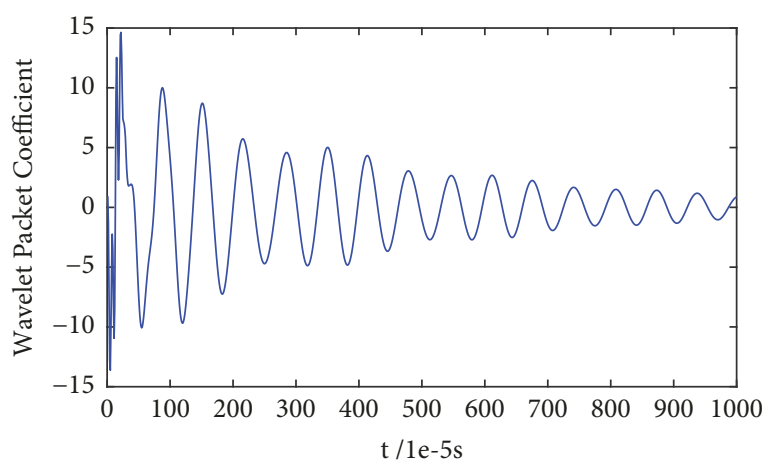

(a) $\operatorname{Knot}(1,0)$

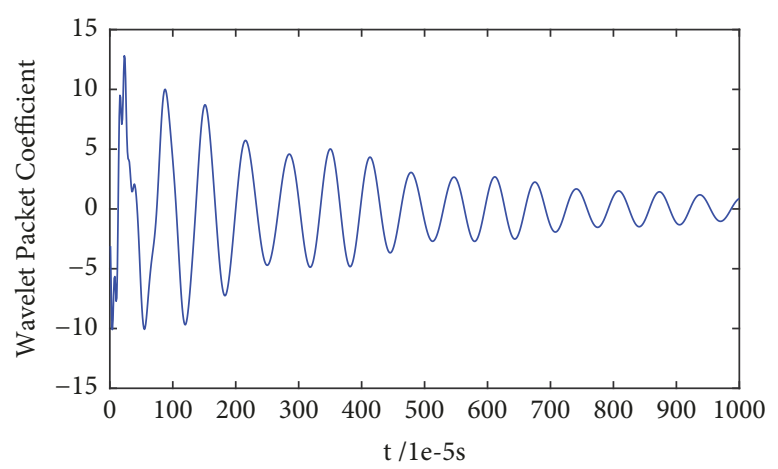

(c) $\operatorname{Knot}(2,0)$

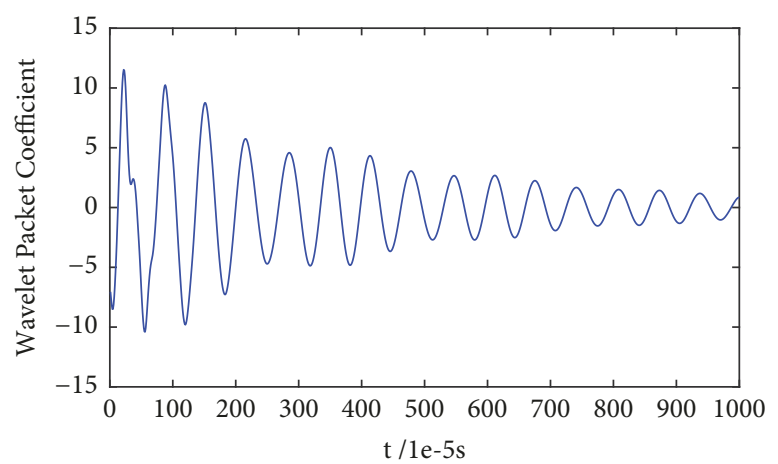

(e) $\operatorname{Knot}(3,0)$

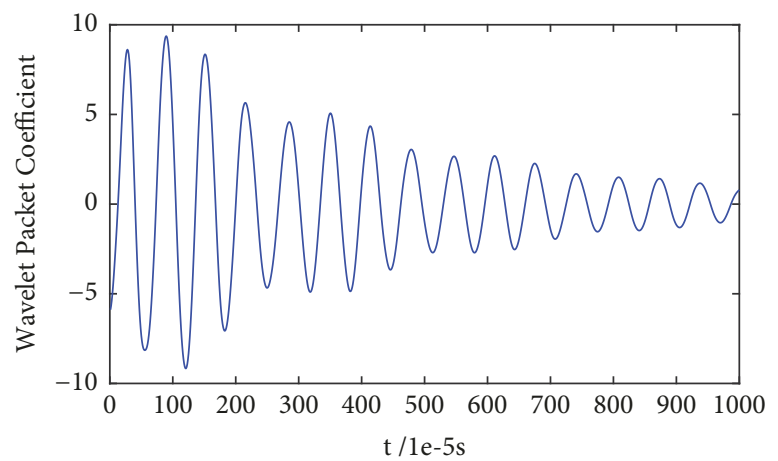

(g) $\operatorname{Knot}(4,0)$

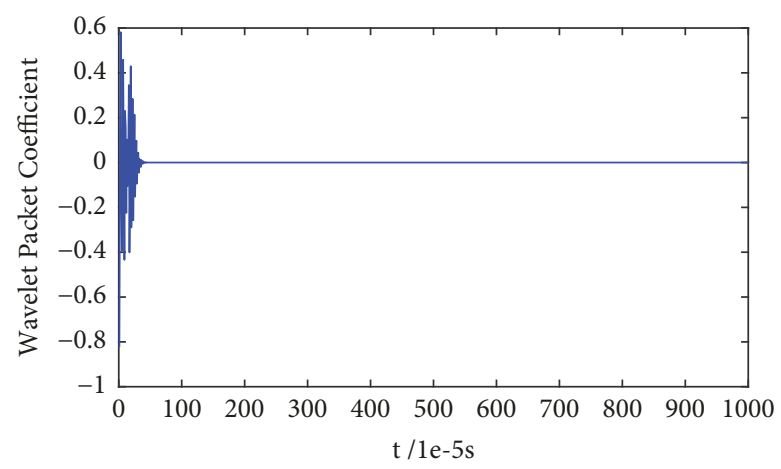

(b) Knot $(1,1)$

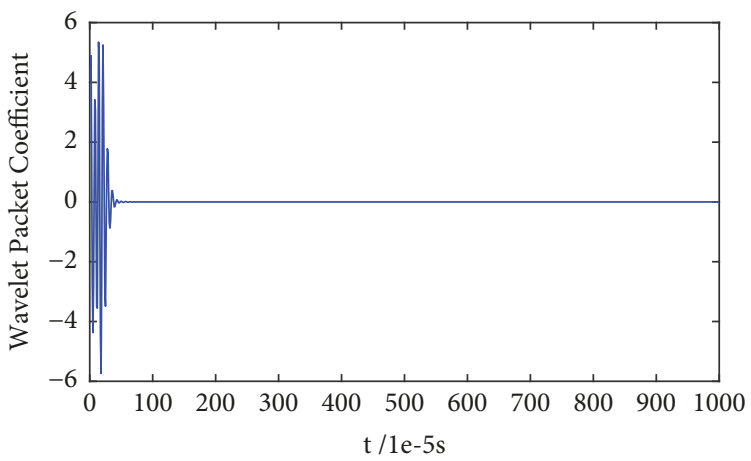

(d) Knot $(2,1)$

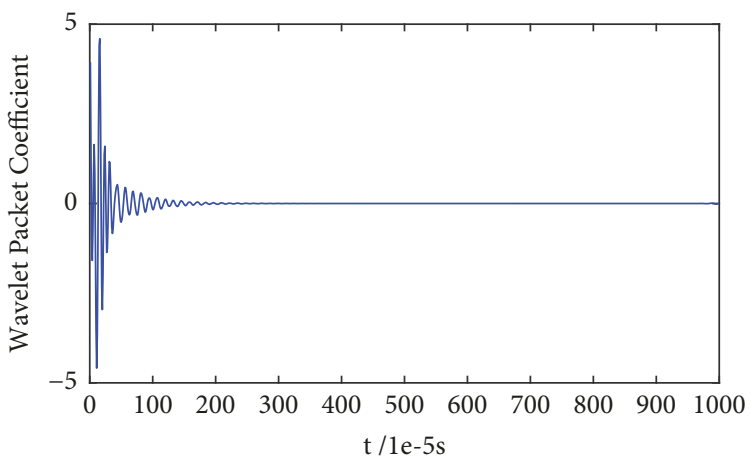

(f) $\operatorname{Knot}(3,1)$

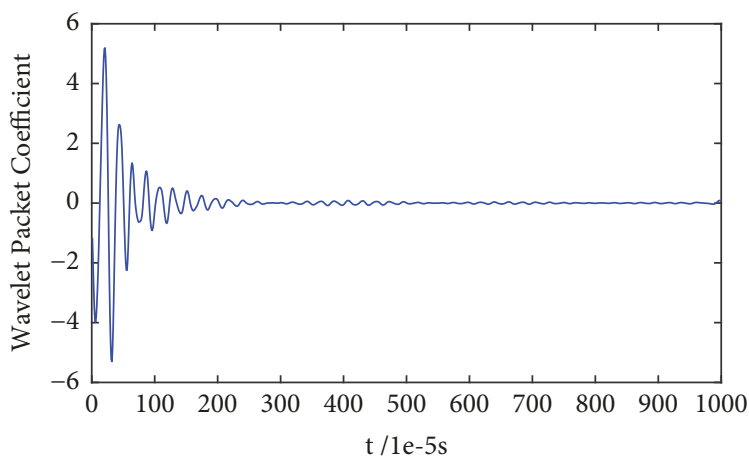

(h) $\operatorname{Knot}(4,1)$

FIGURE 21: Wavelet packet coefficients corresponding to the 24th node in case S1 in Example 2. 
energy of each decomposed component signal. Then the ECD index can be obtained. With the illustration of the ECD index curve, the damage location and damage severity can be identified effectively. Two numerical examples are used to demonstrate the applicability of the proposed ECD index for damage identification. The ECD index is sensitive to low damage levels because even $5 \%$ stiffness reduction can be apparently identified by it. The mutation on the ECD index curve can identify the damage accurately, which is demonstrated by the illustration of damage elements in the finite element model. The results of this study indicate that the proposed ECD index can be employed to effectively identify the damage to structures for engineering applications.

\section{Conflicts of Interest}

There are no conflicts of interest related to this paper.

\section{References}

[1] Y. J. Yan, L. Cheng, Z. Y. Wu, and L. H. Yam, "Development in vibration-based structural damage detection technique," Mechanical Systems and Signal Processing, vol. 21, no. 5, pp. 2198-2211, 2007.

[2] J. T. Kim and N. Stubbs, "Improved damage identification method based on modal information," Journal Sound and Vibration, vol. 252, no. 2, pp. 223-238, 2002.

[3] J.-T. Kim, Y.-S. Ryu, H.-M. Cho, and N. Stubbs, "Damage identification in beam-type structures: frequency-based method vs mode-shape-based method," Engineering Structures, vol. 25, no. 1, pp. 57-67, 2003.

[4] U. Lee and J. Shin, "A frequency response function-based structural damage identification method," Computers \& Structures, vol. 80, no. 2, pp. 117-132, 2002.

[5] S. Kim, W. Jeong, and J. Cho, "A frequency response functionbased damage identification method for cylindrical shell structures," Journal of Mechanical Science \& Technology, vol. 18, no. 12, pp. 2114-2124, 2013.

[6] Y. Toyosaki, Y. Nariyuki, and T. Minamoto, "Analytical study on damage identification of composite girder bridges based on changes in primary mode shape," Journal of Japan Association for Earthquake Engineering, vol. 16, no. 1, pp. 238-247, 2016.

[7] H. Kim and H. Melhem, "Damage detection of structures by wavelet analysis," Engineering Structures, vol. 26, no. 3, pp. 347362, 2004.

[8] Z. Hou, M. Noori, and R. S. Amand, "Wavelet-based approach for structural damage detection," Journal of Engineering Mechanics, vol. 126, no. 7, pp. 677-683, 2000.

[9] I. Daubechies and C. Heil, Ten Lectures on Wavelets, Capital City Press, 1992.

[10] I. Daubechies, "The wavelet transform, time-frequency localization and signal analysis," Journal of Renewable \& Sustainable Energy, vol. 36, no. 5, pp. 961-1005, 2015.

[11] W. L. Bayissa, N. Haritos, and S. Thelandersson, "Vibrationbased structural damage identification using wavelet transform," Mechanical Systems and Signal Processing, vol. 22, no. 5, pp. 1194-1215, 2008.

[12] J. Grabowska, M. Palacz, and M. Krawczuk, "Damage identification by wavelet analysis," Mechanical Systems and Signal Processing, vol. 22, no. 7, pp. 1623-1635, 2008.
[13] U. P. Poudel, G. Fu, and J. Ye, "Wavelet transformation of mode shape difference function for structural damage location identification," Earthquake Engineering \& Structural Dynamics, vol. 36, no. 8, pp. 1089-1107, 2010.

[14] M. Haase and J. Widjajakusuma, "Damage identification based on ridges and maxima lines of the wavelet transform," International Journal of Engineering Science, vol. 41, no. 13-14, pp. 14231443, 2003.

[15] M. M. Alamdari, J. Li, and B. Samali, "Damage identification using 2-D discrete wavelet transform on extended operational mode shapes," Archives of Civil \& Mechanical Engineering, vol. 15, no. 3, pp. 698-710, 2015.

[16] G. P. Nason, Wavelet Packet Transform, Springer Press, 2011.

[17] Z. Sun and C. C. Chang, "Structural damage assessment based on wavelet packet transform," Journal of Structural Engineering, vol. 128, no. 10, pp. 1354-1361, 2002.

[18] J.-G. Han, W.-X. Ren, and Z.-S. Sun, "Wavelet packet based damage identification of beam structures," International Journal of Solids and Structures, vol. 42, no. 26, pp. 6610-6627, 2005.

[19] Y.-L. Ding, A.-Q. Li, and Y. Deng, "Structural damage warning of a long-span cable-stayed bridge using novelty detection technique based on wavelet packet analysis," Advances in Structural Engineering, vol. 13, no. 2, pp. 291-298, 2010.

[20] R. Prakash and S. M. Srinivasan, "Wavelet packet transform based damage identification of GFRP beam," Journal of Structural Engineering (India), vol. 40, no. 1, pp. 44-47, 2013.

[21] X. Wang, W. B. Hu, and Z. B. Meng, "Damage alarming analysis for ancient wood structures based on wavelet packet energy spectrum," Multidiscipline Modeling in Materials and Structures, vol. 10, no. 4, pp. 593-610, 2014.

[22] Z. Jiang and B. Chen, "Performance degradation assessment of a beam structure by using wavelet packet energy," Applied Mechanics and Materials, vol. 166-169, pp. 1102-1107, 2012.

[23] T. Liu, A. Q. Li, and Y. L. Ding, "Alarming method for cable damage of long-span cable-stayed bridges based on wavelet packet energy spectrum," Journal of Southeast University, vol. 37, no. 2, pp. 270-274, 2007.

[24] X. J. Liu, L. Sun, S. X. Zhang, R. Z. Shi, and Z. B. Meng, "Application of improved wavelet packets index to structural damage detection," Mechanical Science and Technology for Aerospace Engineering, vol. 35, no. 5, pp. 657-661, 2016.

[25] X. J. Liu, K. R. Shang, S. X. Zhang, B. Huo, and L. Sun, "Damage detection method for beam structures based on improved wavelet packet energy," Journal of Vibration and Shock, vol. 35, no. 13, pp. 179-185, 2016.

[26] P. Chang, N. Yang, and G. P. Zhang, "Damage identification of the frame structure based on multi-resolution analysis and wavelet energy curvature," Journal of Harbin Institute of Techno$\log y$, vol. 48, no. 6, pp. 170-176, 2016.

[27] X. Wang, W. B. Hu, and Z. B. Meng, "Damage detection of an ancient wood structure based on wavelet packet energy curvature difference," Journal of Vibration and Shock, vol. 33, no. 7, pp. 153-159, 2014.

[28] Z. Yu, H. Xia, J. M. Goicolea, and J. W. Zhan, "Experimental study on bridge damage identification based on wavelet packet energy curvature difference method," Journal of Vibration and Shock, vol. 32, no. 5, pp. 20-25, 2013.

[29] Z. L. Wang and G. H. Nie, "A method for structure damage detection based on curvature mode and wavelet packet transformation," Journal of Vibration and Shock, vol. 27, no. 1, pp. 124126, 2008 (Chinese). 


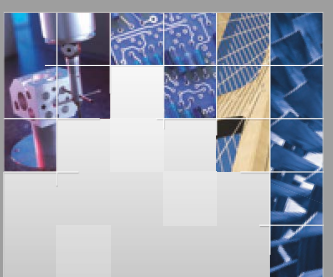

\section{Enfincering}
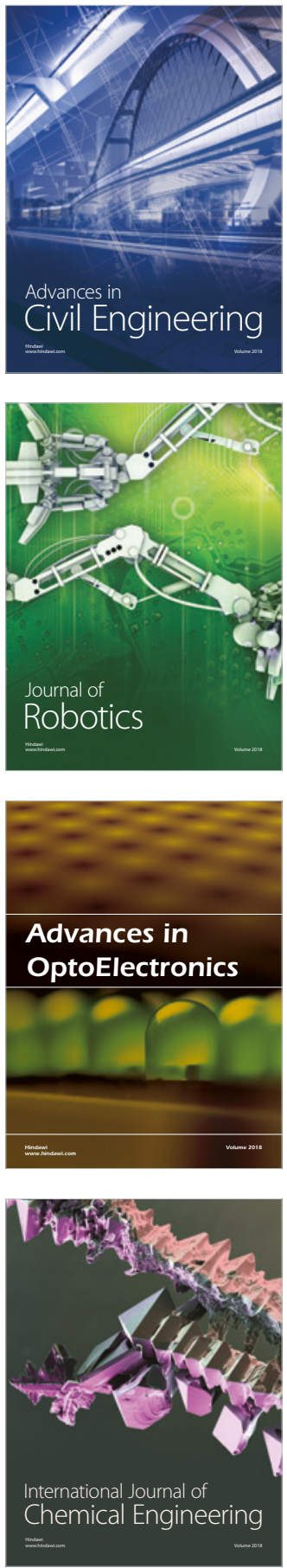

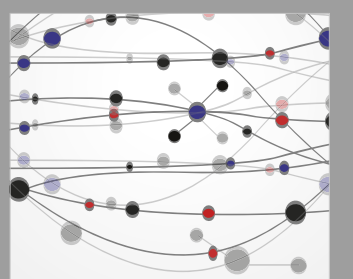

\section{Rotating \\ Machinery}

The Scientific World Journal

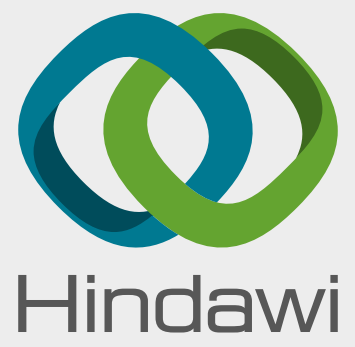

Submit your manuscripts at

www.hindawi.com
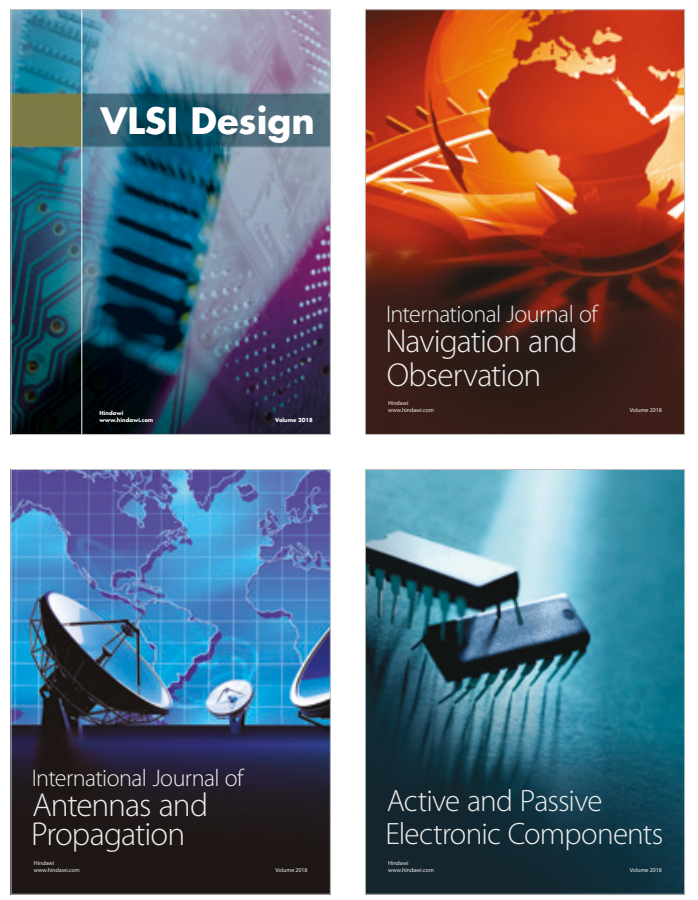
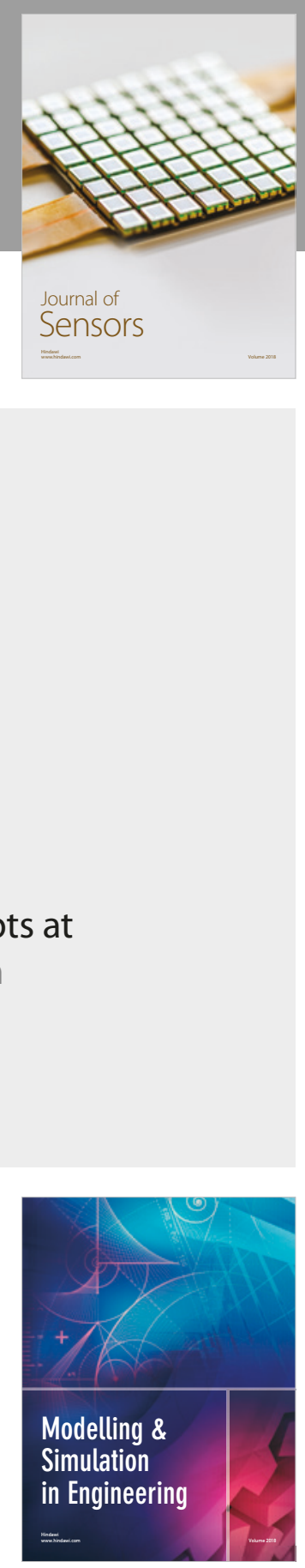

\section{Advances \\ Multimedia}
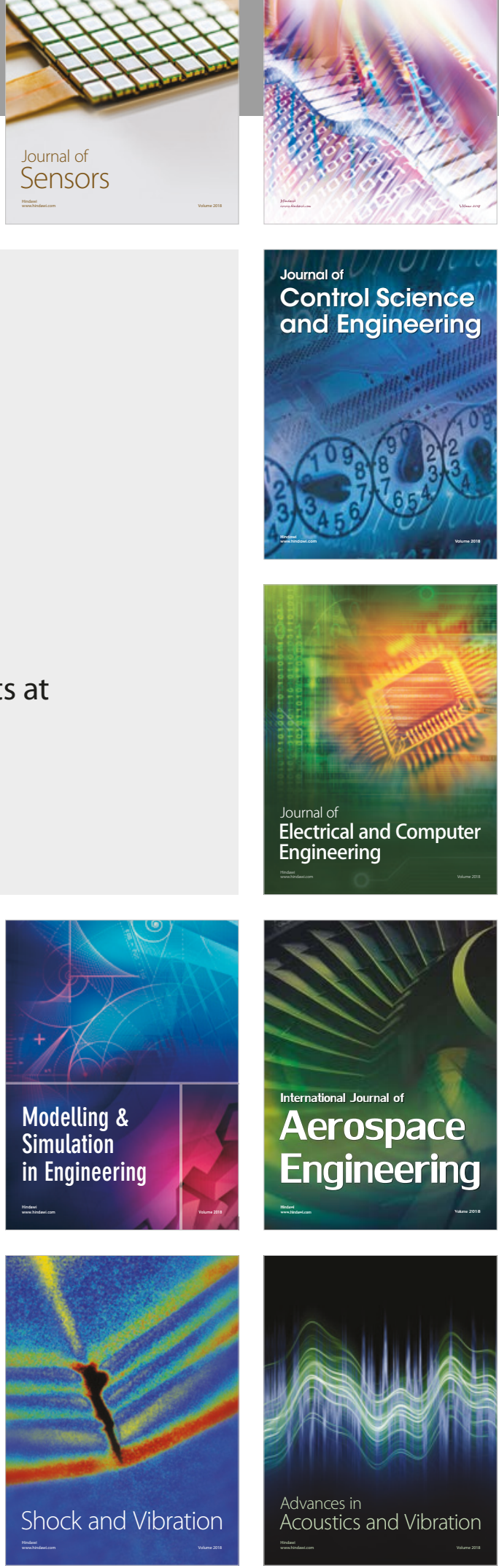